\title{
Invisible wounds from the Congo war
}

$\mathrm{P}$ ascal's gaze is watery and distant, the whites of his eyes red, and his slow, slurred speech gives his listeners the distinct impression that he is heavily drugged.

The 25-year-old is a former Mai Mai soldier. The Mai Mai, famed for their belief that witchcraft keeps them safe during warfare, are a group of armed men who operate in the Democratic Republic of Congo in the gaps between the rebels and the national government, alternately to protect defenceless villagers and to extort them for money and food.

Pascal is a patient at Sosame, short for Soins de Santé Mental, a psychiatric institution in the city of Bukavu, in eastern Congo. He tells other patients, "I can have Nkunda flown in here at any moment," referring to Laurent Nkunda, general of the Rwanda-backed rebel group Congres National pour la Défense $d u$ Peuple. His words are met with scornful laughter. His uncle, Albert, apologizes, "If he were right in the head, he would not want to be a Mai Mai soldier again. That is his illness."

Sosame is the scene of an uneasy coexistence between witchcraft and modern psychiatry in Bukavu, built Riviera-style into the hills surrounding the southern tip of Lake Kivu in the province of South Kivu. It has clearly seen better times; it was a popular vaca-

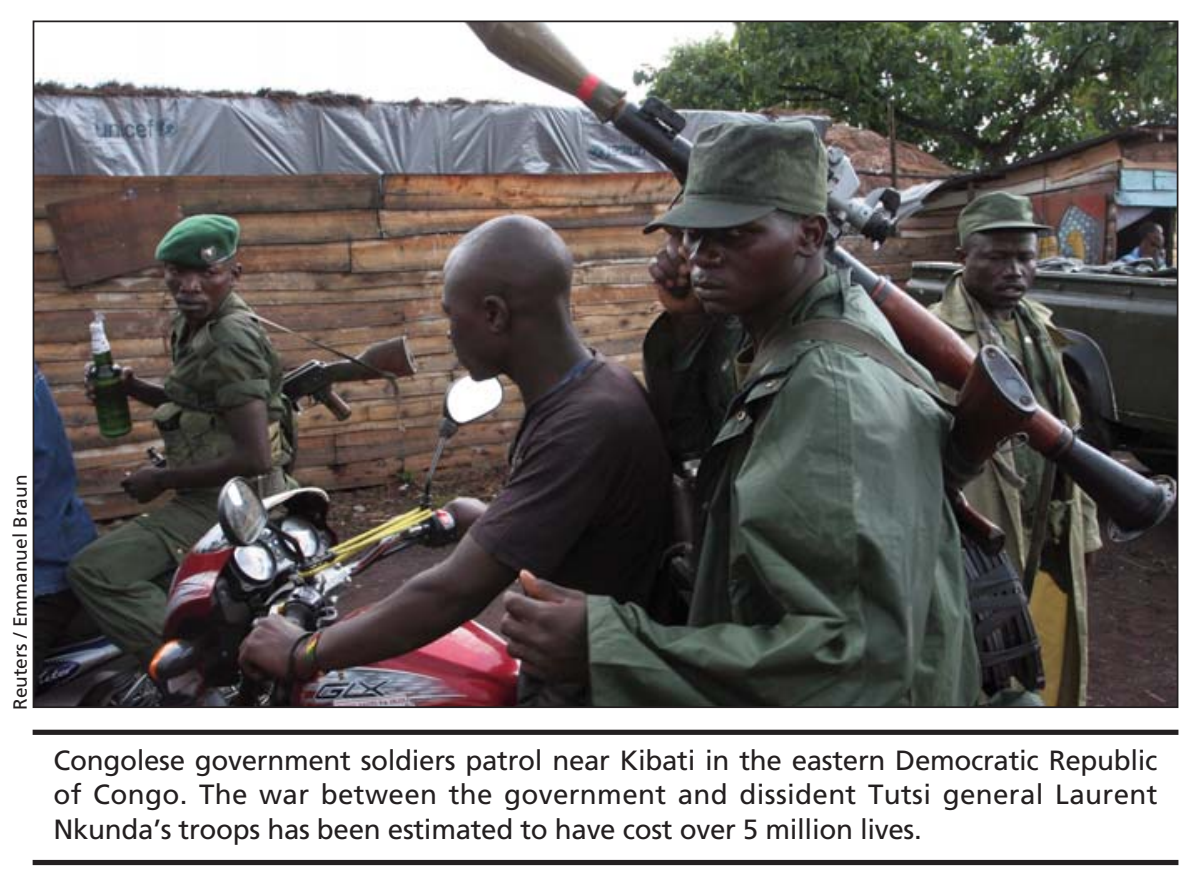

Congolese government soldiers patrol near Kibati in the eastern Democratic Republic of Congo. The war between the government and dissident Tutsi general Laurent Nkunda's troops has been estimated to have cost over 5 million lives.

tion destination for well-to-do Europeans in the 1960s. Deep potholes pockmark the roads and make for slow going. The countryside, a green patchwork of cultivated land, looks picture-perfect, belying a traumatic history of a decade-long conflict between rebels, the central government and other opportunists.

Congo is ground zero of what has been called "Africa's First World War," having drawn in forces from Angola, Burundi, Namibia, Rwanda, Uganda and Zimbabwe. According to a study conducted by the International Rescue Committee, a humanitarian aid organization, more than 5 million people have died in the war. Its root cause is the genocide in neighbouring Rwanda, where, in 1994, Hutus killed Tutsis en masse. The Hutu militia, the Interhamwe, escaped to Congo, pursued by the Tutsis. The ensuing war lasted from 1998 to 2003, but lawlessness, the torching of villages, rape and murder have persisted. In early May, the Interhamwe attacked the village of Ekingi, about $80 \mathrm{~km}$ northwest of Bukavu, and the village of Busurungi, killing more than 90 people. According to the United Nations, 120000 people were displaced between March and May.

Sosame faces the daunting task of treating a population in the midst of a conflict; people are suffering from illnesses, such as post-traumatic stress dis- order, depression and anxiety. The staff battle the security risks of operating in an unstable country and the challenge of being a state hospital in a land crippled by political upheaval. Public funds are more likely to find their way into bureaucratic pockets than into public mental health facilities.

Though Bukavu itself has a population of only 240000 , South Kivu province is home to 6 million, and Sosame is its only psychiatric hospital.

"My only wish is that there were more psychiatric health centres like Sosame so we could have fewer patients," says Dr. Benjamin Bihabwa, one of the centre's 3 doctors. The center houses about 100 inpatients and serves 50 to 60 out-patients daily. The doctors estimate that roughly half of the inpatients are there as a result of trauma attributable to war: witnessing violence against family or friends; sexual violence, often combined with being taken hostage; repeated displacement; and torture. They are often fleeing bombings, shootings and pillaging. Other patients suffer from epilepsy, autism, schizophrenia, depression and other mental or neurological diseases.

Sosame policy requires that each inpatient be accompanied by a same-sex family member who can nurse them during their stay, serving as caregiver, cook, driver and source of funds. In the Congo, family care and support are typically required for medical treatment.

Sosame's only non-Congolese staff member, Brother Johan Bultinck, a Belgian member of the Brothers of Charity and a psychiatric nurse, founded the hospital when he began nursing the mentally ill in Bukavu's camps for the displaced in 1994. Sosame has never turned a patient away, even when the hospital is swelled beyond capacity. In that event, Brother Johan says, they simply drag out extra mattresses and place them on the floor. Those patients who are unable to pay for their treatment, roughly US $\$ 30$ for an average stay of 6 weeks, do odd jobs, such as working in the garden.

The hospital staff are paid US\$8 per month by the government. Their salaries are supplemented by groups like CARAES, a Dutch nongovernmental 
organization. The boxes of medication - purchased by CARAES - in the stockroom bear return address labels from Belgium and Italy.

Sosame and the western medicine it espouses live an uneasy coexistence with widespread traditional beliefs in witchcraft. Many of the patients who eventually find their way to the hospital have exhausted medicinal options offered by village witch doctors.

"Traditional medicine and healers are the main reason why people often come very late [to Sosame]," says Dr. Lothar Winkler, head of Malteser International in Bukavu, a funder and partner organization of Sosame. Many believe that "if somebody goes mad, there is a reason, and surely the reason is that there is witchcraft behind it. [They believe] what comes from witchcraft has to be healed by witchcraft. This is one of the reasons why it is so important to introduce mental health care in the 'normal' services of all health facilities."

Bénézet Bujo, a theologian from the Roman Catholic Diocese of Bunia, says the Congolese call traditional healing ufumu, and sorcery ulozi, and they blame both concepts interchangeably for a range of misfortunes, from disturbing dreams to sudden death to mental illness. Further confounding the 2 concepts, is that practitioners of ufumu and ulozi are usually the same person. In Christian circles, the benefits of ufumu healing are rarely acknowledged outside of academic discussion, though it is an undeniable fact that patients often use it.

"People still think of mental health as part of the spiritual world," Brother Johan says.

Sosame's patients offer explanations shrouded in mystery for their illnesses. For example, one female patient says her problems began when she felt a tap on her shoulder, only to turn around and see no one. Another patient says he is mentally ill because he is the sixth child, while a woman says her daughter became autistic after striking her head on a rock.

The issue of cooperation among traditional healers, herbalists, and witch doctors was discussed in the First Pan African Psychiatric Conference in 1961, but it remains a riddle, according to the World Health Organization. Many patients still have deeply rooted

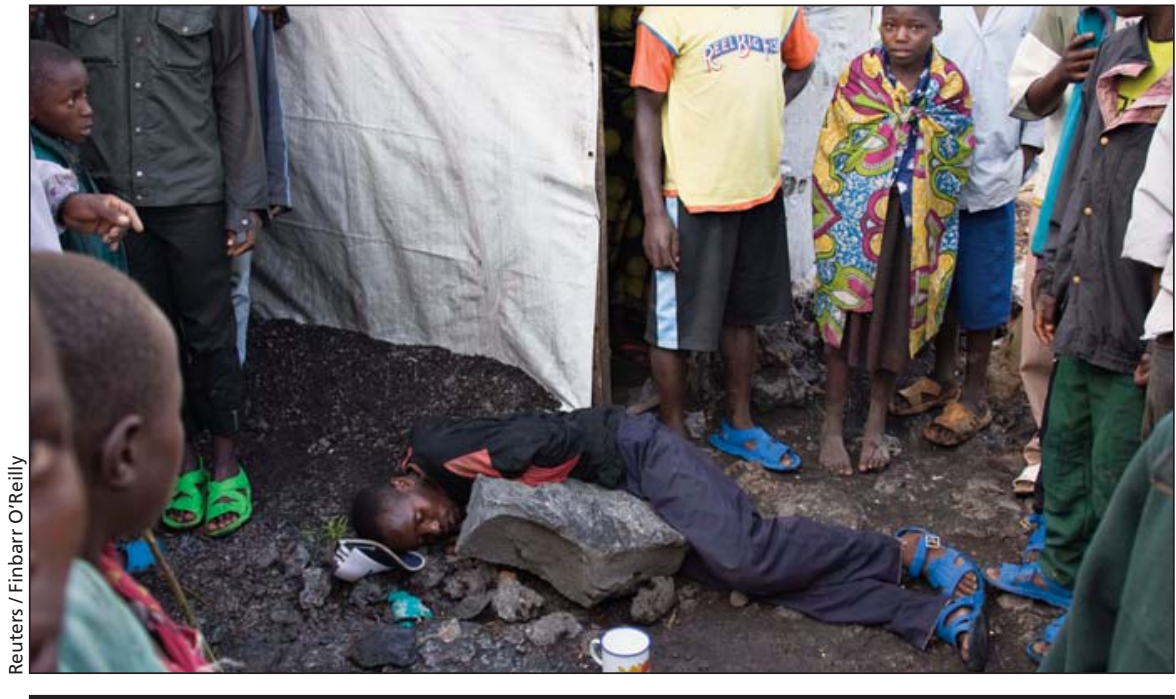

Onlookers gather around the body of a refugee who died during heavy gunfire at a camp for dispaced people in the eastern Congo.

suspicions toward western medical practices in general but often simultaneously have unrealistic expectations of rapid and complete cures. The attitudes are apparent in how patients cite their drugs, not the slower-going doctor consultations or ergotherapy (the use of games, chores and arts as therapy) as the reason for their recoveries.

Justin Iukika, health project assistant at Malteser International, is on a follow-up visit to Kanyola, a few hours' drive from Bukavu. The Congolese, dispersed over a land mass roughly the size of Western Europe, struggle with often impassable dirt roads. The provision of rides to and from a hospital by an aid organization can mean the difference between recovery and illness. Malteser International provides such rides and conducts home follow-up visits after patients have left Sosame to gauge reintegration into home life.

Justin greets Gigokere, who looks out from his small thatch-roofed hut with a vacant, wide-eyed stare. The 55-year-old was shot by Interhamwe soldiers in 2006 while defending his older brother, who was shot and killed. Asked where his brother was killed, Gigokere points to an adjacent plot separated from his compound by a row of plants. Since then, Gigokere's eldest son and wife say, he has never been the same. After his gunshot wound healed, he began beating his children, saying incomprehensible things, and his "head was not correct."
On a broader scale, the violence in eastern Congo has spurred high rape rates. According to Refugee Law Project, a Uganda-based organization, roughly 1 in 3 women in eastern Congo has been raped.

Back at Sosame, a 23-year-old woman sits in a stuffy bedroom suffering from post-traumatic stress disorder. The room is shared by 5 patients and has curtains drawn over its windows, throwing it in muted, coloured shadow. In one hand, she holds a partially peeled orange, while a syringe — filled with "reanimation liquid," explains Dr Pontifa Isanda — is implanted in her other wrist.

Staff social worker Noelle Muderhwa explains that the woman was 14 years old when she and her older sister were taken hostage from their home by the Interhamwe, after having watched her sister's husband killed. Over the course of the next 2 years, she was raped repeatedly by the soldiers and gave birth to a child. He now seems to be a bright-eyed 3-year-old boy, with a winning smile.

The woman awkwardly separates the orange, the mobility of her hands compromised by the syringe, and hands him half. He eats happily seated next to his mother, unaware that her silence, her inability to meet anyone's gaze, and the syringe in her left wrist are anything out of the ordinary. - Soo-Ryun Kwon, Bukavu, Democratic Republic of Congo

DOI:10.1503/cmaj.090930 